\title{
Relationship of Stress, Distress, and Inadequate Coping Behaviors to Periodontal Disease
}

\author{
R.J. Genco, ${ }^{*}$ A.W. Ho, ${ }^{*}$ S.G. Grossi, ${ }^{*}$ R.G. Dunford, ${ }^{*}$ and L.A. Tedesco ${ }^{\dagger}$
}

Background: The association of stress, distress, and coping behaviors with periodontal disease was assessed.

Methods: A cross-sectional study of 1,426 subjects between the ages of 25 and 74 years in Erie County, New York, was carried out to assess these relationships. Subjects were asked to complete a set of 5 psychosocial questionnaires which measure psychological traits and attitudes including discrete life events and their impact; chronic stress or daily strains; distress; coping styles and strategies; and hassles and uplifts. Clinical assessment of supragingival plaque, gingival bleeding, subgingival calculus, probing depth, clinical attachment level (CAL) and radiographic alveolar crestal height $(\mathrm{ACH})$ was performed, and 8 putative bacterial pathogens from the subgingival flora measured.

Results: Reliability of subjects' responses and internal consistencies of all the subscales on the instruments used were high, with Cronbach's alpha ranging from 0.88 for financial strain to 0.99 for job strain, uplifts, and hassles. Logistic regression analysis indicated that, of all the daily strains investigated, only financial strain was significantly associated with greater attachment and alveolar bone loss (odds ratio, $\mathrm{OR}=1.70,95 \% \mathrm{CI}=1.09$ to 2.65 and $\mathrm{OR}=1.68,95 \% \mathrm{CI}$ $=1.20$ to 2.37 , respectively) after adjusting for age, gender, and cigarette smoking. When coping behaviors were evaluated, it was found that those with more financial strain who were high emotion-focused copers (a form of inadequate coping) had a higher risk of having more severe attachment loss ( $O R=2.24$, $95 \% \mathrm{CI}=1.15$ to 4.38$)$ and alveolar bone loss $(\mathrm{OR}=1.91,95 \% \mathrm{CI}=1.15$ to 3.17 ) than those with low levels of financial strain within the same coping group, after adjustment for age, gender, and cigarette smoking. Similar results were found among the low problem-focused copers for $\mathrm{AL}(\mathrm{OR}=2.21,95 \% \mathrm{CI}=1.11$ to 4.38$)$ and $\mathrm{ACH}(\mathrm{OR}=2.12,95 \% \mathrm{CI}=1.28$ to 3.51$)$. However, subjects with high levels of financial strain who reported high levels of problem-based coping (considered adequate or good coping) had no more periodontal disease than those with low levels of financial strain, suggesting that the effects of stress on periodontal disease can be moderated by adequate coping behaviors.

Conclusions: We find that psychosocial measures of stress associated with financial strain and distress manifest as depression, are significant risk indicators for more severe periodontal disease in adults in an age-adjusted model in which gender (male), smoking, diabetes mellitus, B. forsythus, and P. gingivalis are also significant risk indicators. Of considerable interest is the fact that adequate coping behaviors as evidenced by high levels of problem-based coping, may reduce the stress-associated risk. Further studies also are needed to help establish the time course of stress, distress, and inadequate coping with respect to the onset and progression of periodontal disease, and the mechanisms that explain this association. J Periodontol 1999;70: 711-723.

\section{KEYWORDS}

Periodontal diseases; stress; adaption, physiological.

\footnotetext{
* State University of New York at Buffalo, School of Dental Medicine, Department of Oral Biology, Periodontal Disease Research Center, Buffalo, NY.

$\dagger$ University of Michigan, School of Dentistry, Ann Arbor, MI.
}

$\mathrm{P}$ eriodontal diseases are inflammatory conditions caused by infection with subgingival bacteria. Analysis of systemic and microbial factors in epidemiological studies points to several risk factors as strongly associated with periodontitis. ${ }^{1,2}$ Periodontal risk factors include age, gender, cigarette smoking, ${ }^{3-16}$ infection with Porphyromonas gingivalis and Bacteroides forsythus, ${ }^{16-19}$ and diabetes mellitus. 2,18,20-22

The possible role of mental and psychosocial entities in oral diseases has become the subject of several case control studies. Morse and coworkers ${ }^{23}$ suggested from a study of 12 subjects that different bacteria levels were found under stress and relaxation conditions, which supports the concept that stress may contribute to dental caries and relaxation may have an anti-caries effect. The relationship between increased work stress and poor oral health status was also reported by Marcenes and Sheiham.24 Green et al. ${ }^{25}$ also studied periodontal disease as a function of life event stress and suggested a relationship between stressors and periodontal disease. Freeman and Goss ${ }^{26}$ sug- 
gested that periodontal disease may be related to psychological factors which affect reactions to stressful life events. A recent report on a subsample of our Erie County risk assessment study population demonstrated, in an exploratory analysis of 71 cases and 77 controls, that periodontal disease subjects scored higher on levels of depression than the control group. ${ }^{27}$ The limitation of these studies is their small sample size which does not allow for adequate adjustment for possible confounding factors such as age, gender, and smoking.

Although the relationships between certain systemic diseases and the occurrence of stressful life events, personality, and coping strategies used by individuals have been studied for many years, there have been no reported studies of the effects of these psychosocial factors on oral and periodontal diseases in a large population which would allow for analysis of possible confounding factors such as age, gender, smoking, and dental care. The aim of this study was to investigate the relationship of periodontal disease to stress, distress, and coping in a large population-based sample of adults. Stress was measured by questionnaires relating to major life events, daily role strains, and hassles and uplifts; distress was measured by a patient symptoms inventory; and coping behavior was measured by a coping scale.

\section{Study Population and Methods}

This study is part of the Erie County Study, designed to determine risk factors for periodontal disease. The study population has been described previously, ${ }^{16,18}$ as has the reliability of the clinical measures. ${ }^{28}$ Briefly, a total of 1,426 subjects ( 741 females and 685 males), between ages 25 and 74, were included using 3 sources of recruitment: 1) subjects from Erie County and Buffalo census tract data to help ensure a distribution of subjects with various socioeconomic characteristics; 2) subjects who presented for treatment at the State University of New York at Buffalo, School of Dental Medicine; and 3) respondents to advertisements in local newspapers for volunteers for a dental study. The latter 2 sources were used to ensure that there were equal numbers of subjects at each decade by age, from 25 to 74 years, resulting in approximately equal numbers of subjects in each of 5 age decades. Rather than population representation, the main objective of this cross-sectional sample was to display a broad variation in periodontal disease severity and in potential risk factors to assess the relationship between explanatory and outcome variables. Accordingly, the study sample included a wide range of periodontal disease severity defined by different levels of attachment loss and different levels of interproximal alveolar bone loss. For some of the analyses, subjects with no attachment loss or radiographic alveolar crestal loss were regarded as controls and those with definite attachment loss and radiographic alveolar crestal loss were considered as cases, thereby allowing the estimation of odds ratios as a measurement of relative risk.

The study was explained to prospective participants and all subjects in the study signed a State University of New York at Buffalo approved informed consent form as well as completed a demographic health-smoking questionnaire prior to clinical examination. The demographic and socioeconomic variables examined included age, gender, years of education, habits, medical and dental history, and household income.

Clinical examination included supragingival plaque and gingival bleeding measurements. Also, probing depth (PD) and clinical attachment level (CAL) at 6 sites on all teeth in the dentition were assessed. ${ }^{16}$ Mean attachment loss (CAL) and radiographic alveolar crestal height $(\mathrm{ACH})$ were also evaluated for each subject. As described in the previous reports, ${ }^{16,18}$ CAL was stratified into 5 ordered categories: healthy $(0$ to $1 \mathrm{~mm}$ CAL), low (1.1 to $2.0 \mathrm{~mm})$, moderate (2.1 to $3.0 \mathrm{~mm}$ ), high (3.1 to $4.0 \mathrm{~mm}$ ) and severe (4.1 to $8.0 \mathrm{~mm}$ ). Alveolar crestal height $(\mathrm{ACH})$, or alternately termed bone loss (ABL) as depicted in Figure 1, was categorized into healthy (0.4 to $1.9 \mathrm{~mm} \mathrm{ACH}$ ), low (2.0 to 2.9 $\mathrm{mm})$, moderate (3.0 to $3.9 \mathrm{~mm})$, and severe $(\geq 4.0$ $\mathrm{mm}$ ). Both CAL and ACH were utilized to define periodontal disease severity. After training and calibration of examiners, the mean intra-examiner variance for CAL was $0.32 \mathrm{~mm} .{ }^{28}$ The average error (standard deviation of duplicate measurements) of interproximal alveolar crestal bone height measurements $(\mathrm{ACH})$ using a computerized methodology for training and calibration of image analyzers developed by Hausmann and cowork$\mathrm{ers}^{29}$ was $0.16 \mathrm{~mm}$.

For measurement of the subgingival flora, subgingival plaque samples were taken from a total of 6 maxillary and 6 mandibular teeth using the paper point technique. ${ }^{30}$ The maxillary and mandibular samples were pooled separately and each of these 2 pooled samples then assayed using immunofluorescence microscopy for the following microorganisms: Actinobacillus actinomycetemcomitans, Bacteroides forsythus, Campylobacter rectus, Capnocytophaga species, Eubacterium saburreum, Fusobacterium nucleatum, Porphyromonas gingivalis, and Prevotella intermedia. ${ }^{30,31}$

A self-reported smoking history was coded and quantified as a composite value of the number of packs of cigarettes smoked per day multiplied by number of years smoked; i.e., the number of packyears (pkyr). ${ }^{16}$ Subjects also were categorized into those who never smoked, occasional or very light smokers (>0 to 5.2 pkyr), light smokers (5.3 to 15.0 pkyr), moderate smokers (15.1 to 30.0 pkyr) and heavy smokers (30.1 to $150.0 \mathrm{pkyr})$. 
After all oral and clinical examinations were completed, subjects were given a set of psychosocial questionnaires which were completed in a private setting in the clinic. Professional staff were available to answer questions. Subjects were assured that their answers would be held in the strictest confidence to help encourage complete and truthful self-reporting. These psychosocial measures included the following 5 instruments: The Life Event Scale ${ }^{32}$ which evaluates life events, including their perceived controllability and impact in the following categories: personal relationships (7 items), childbirth (8 items), work (9 items), finances ( 8 items), health and illness ( 7 items), crime and legal matters (8 items), residential and household events ( 7 items), and education ( 5 items). The second instrument was the Measures of Chronic Stress (Daily Strains) adapted from the Problems of Everyday Living Scale of Pearlin and Schooler. ${ }^{33}$ This scale assesses chronic stressors associated with the central roles people occupy in life: spouse, parent, worker, and financial manager. We used 80 of the original 84 items for our study. The third scale was Measures of Distress, the Brief Symptom Inventory (BSI) of Derogatis and Spencer. ${ }^{34}$ This is a 53 -item, self-report psychometric instrument with well-established reliability and validity and is based on the Hopkins-Symptom Checklist 90revised (SCL-90-R). Psychological and somatic symptom patterns are assessed along the following 9 symptom dimensions: somatization (7 items), obsessive-compulsive (6 items), interpersonal sensitivity (4 items), depression (6 items), anxiety (6 items), hostility (5 items), phobic anxiety (5 items), paranoid ideation (5 items), and psychoticism (5 items). The fourth instrument used was Coping Styles and Strategies which includes 60 items to measure the ways in which individuals attempt to face, reduce, or master the challenge presented by stressful experiences. ${ }^{35}$ Twenty items each measure aspects of problem-focused coping and of emotion-focused coping, while 12 items measure coping responses that can be described as less productive or less useful ways of coping. Finally, Hassles and Uplifts measures how much things annoy, bother, satisfy, or are joyful to an individual in day-today life. ${ }^{36}$ Subscales that were included in this instrument are general hassles and uplifts (49 items were used for each subscale), and health hassles and health uplifts ( 5 items for each subscale). Respondents were asked to report on a various pointing scale, depending on which instruments, how many life events or how much impact, control, discomfort, uplifts, or hassles they had experienced to each of the items. Scores were calculated accordingly for each subject to determine the level of symptomology. The higher the score on a measure, the worse the trait; e.g., in BSI, the higher the score, the greater the feelings of distress.

\section{Statistical Analysis}

We assessed the validity of the collected psychosocial data from our study population to the hypothetical factor structures and internal consistency of items within each subscale or individual psychosocial instrument. Factor analysis with varimax rotation technique and Cronbach's alpha were utilized accordingly for these purposes. ${ }^{37,38}$ Analysis of covariance was employed to examine the differences in all psychosocial scores of each subscale between various levels of attachment and independently for each level of alveolar bone loss after adjusting for gender and other known risk factors such as age and cigarette smoking. Finally, ordinal logistic regression models were used to measure the association of the outcome variables, namely clinical attachment loss (CAL) and interproximal alveolar crestal bone height $(\mathrm{ACH})$, and other explanatory variables which included age, gender, race, education, smoking, subgingival microorganisms, occupational hazards, systemic diseases, and psychosocial factors. Three systemic diseases (diabetes, allergy, and anemia), which were identified as significant risk indicators for CAL in the previous report, ${ }^{16}$ were introduced into the logistic model. Those variables with a significance level of 0.10 or less were entered into the model in a stepwise approach. We then used the study group median to stratify the subjects into "high" and "low" emotionfocused copers, and problem-focused copers. Further regression analysis was performed to assess the association between severity of CAL and $\mathrm{ACH}$, and daily strains of individuals reporting "high" and "low" emotion-focused or problem-focused coping behaviors. Clinical attachment levels were dichotomized into 2 groups: healthy/low and high/severe, whereas alveolar crestal heights were dichotomized by combining healthy and low $\mathrm{ACH}$, and the moderate and severe $\mathrm{ACH}$. Odds ratios (OR) and the corresponding 95\% confidence intervals $(\mathrm{CI})$ were also calculated.

\section{RESULTS}

A total of 1,426 subjects ( 741 females and 685 males), predominantly Caucasian, between the ages of 25 and 74 years, participated in this study (Table 1). Sixty-five subjects did not have a measurement of alveolar bone loss and thus were excluded from the analysis in assessing the risk of $\mathrm{ACH}$. There were slightly more females than males ( $52 \%$ versus $48 \%$ ), and a high proportion of subjects completed college, although the yearly household income was low $(<\$ 30,000$; Table 1$)$.

Table 2 shows the number of psychosocial items in subscales comprising the Daily Strains and Coping questionnaires, and the results of internal consistency of those items within each subscale and instrument. There were a total of 80 items for Daily Strain: 19 for job, 5 for financial, 16 for spouse, 7 for being single, and 33 for children. Coping Styles and Strategies included prob- 
Table I.

\section{Demographic and Socioeconomic Characteristics of Subjects}

\begin{tabular}{lcc}
\hline & Attachment Loss & Alveolar Bone Loss \\
\hline Subjects & 1,426 & $1,36 \mid$ \\
Age (mean \pm sd) & $48.9 \pm 13.9$ & $48.9 \pm \mid 4.0$ \\
Gender (\%) & & \\
Female & 52.0 & 51.1 \\
Male & 48.0 & 48.9 \\
Race (\%) & & \\
African-American & 6.3 & 6.5 \\
Caucasian & 91.1 & 90.9 \\
Other & 2.6 & 2.6 \\
Education (\%) & & \\
High school & 41.1 & 41.6 \\
College & 58.9 & 58.4 \\
Income (\%) & & \\
$<\$ 30,000$ & 56.7 & 57.2 \\
$\geq \$ 30,000$ & 43.3 & 42.8 \\
\hline
\end{tabular}

lem-focused coping and emotion-focused coping (20 items each), and less effective or bad coping (12 items). Nine subscales were formed from 49 items of Brief Symptom Inventory (Table 3), whereas 49 items each were used for the 2 subscales of the Uplifts and Hassles instrument (Table 4). Besides the financial strain, which had a Cronbach coefficient of 0.88 , all other subscales of Daily Strain and Coping instruments had coefficients over 0.93 (Table 2). Similarly, high Cronbach coefficients were recored for all the subscales in the Brief Symptom Inventory and Uplifts and Hassles questionnaire (Table 4).

Factor analysis using varimax rotation was carried out to further assess goodness of fit of data to the original or hypothetical factor (or subscale) structures (data not shown). The loadings (analogs to correction coefficients) of Daily Strain items on most of the factors were reasonably high, showing that the related items in each subscale cluster together. The exception were the items related to strain of being single, where the items were clustered, but with lower coefficients. The patterns of relationship of BSI and Coping Style items showed that they clustered together with good correlation.

The mean psychosocial scores of each of the subscales after adjusting for the effects of age, gender, and smoking are shown for different severities of attachment loss in Table 5, and levels of bone loss in Table 6. Subjects who suffered more severe CAL and ACH had higher job and financial strain scores than the predominantly healthy subjects. The differences, however, were statistically significant only for those with moderate CAL
Table 2.

\section{Cronbach Coefficient for Daily Strain and Coping Variables}

\begin{tabular}{lcc}
\hline Variable & N Items & Cronbach $\alpha$ \\
\hline Strain & & \\
Job & 19 & 0.9887 \\
Financial & 5 & 0.8828 \\
Spouse & 16 & 0.9850 \\
Being single & 7 & 0.9800 \\
Children & 33 & 0.9844 \\
Role strain composite & 80 & 0.9667 \\
Coping & & \\
Problem-focused & 20 & 0.9652 \\
Emotion-focused & 20 & 0.9555 \\
Bad & 12 & 0.9301 \\
\hline
\end{tabular}

Table 3.

Cronbach Coefficient for Brief Symptom Inventory (BSI) Variables

\begin{tabular}{lcc}
\hline BSI & N Items & Cronbach $\alpha$ \\
\hline Anxiety & 6 & 0.9315 \\
Somatization & 7 & 0.9526 \\
Interpersonal sensitivity & 4 & 0.9194 \\
Psychoticism & 5 & 0.9178 \\
Paranoid ideation & 5 & 0.9179 \\
Depression & 6 & 0.9403 \\
Hostility & 5 & 0.9213 \\
Phobic anxiety & 5 & 0.9491 \\
Obsessive-compulsive & 6 & 0.9307 \\
\hline
\end{tabular}

\section{Table 4.}

\section{Cronbach Coefficient for Uplifts and Hassles Variables}

\begin{tabular}{lcc}
\hline Variables & N Items & Cronbach $\alpha$ \\
\hline Uplifts & 49 & 0.9867 \\
Hassles & 49 & 0.9895 \\
Health uplifts & 4 & 0.8913 \\
Health hassles & 4 & 0.9121 \\
\hline
\end{tabular}




\section{Table 5.}

\section{Adjusted Psychosocial Scores (Mean \pm SE) by Severity of Attachment Loss}

\begin{tabular}{|c|c|c|c|c|c|}
\hline \multirow[t]{2}{*}{ Psychological Scale } & \multicolumn{5}{|c|}{ Attachment Loss } \\
\hline & Healthy & Low & Moderate & High & Severe \\
\hline \multicolumn{6}{|l|}{ Life Events } \\
\hline Number of events & $2.33 \pm 0.32$ & $2.76 \pm 0.11$ & $2.59 \pm 0.12$ & $2.23 \pm 0.21$ & $2.11 \pm 0.25$ \\
\hline Control ratings & $0.26 \pm 0.03$ & $0.25 \pm 0.01$ & $0.25 \pm 0.01$ & $0.22 \pm 0.02$ & $0.24 \pm 0.02$ \\
\hline Impact ratings & $0.24 \pm 0.02$ & $0.24 \pm 0.01$ & $0.23 \pm 0.01$ & $0.21 \pm 0.01$ & $0.21 \pm 0.02$ \\
\hline \multicolumn{6}{|l|}{ Daily Strains } \\
\hline Job strain & $2.12 \pm 0.05$ & $2.09 \pm 0.02$ & $2.16 \pm 0.02$ & $2.09 \pm 0.05$ & $2.22 \pm 0.05$ \\
\hline Financial strain* & $1.66 \pm 0.09$ & $1.83 \pm 0.03$ & $1.94 \pm 0.04$ & $1.98 \pm 0.06$ & $1.98 \pm 0.07$ \\
\hline Spouse strain & $1.90 \pm 0.09$ & $1.87 \pm 0.03$ & $1.99 \pm 0.03$ & $1.93 \pm 0.06$ & $1.85 \pm 0.07$ \\
\hline Being single strain & $1.96 \pm 0.12$ & $1.87 \pm 0.04$ & $1.81 \pm 0.04$ & $1.71 \pm 0.07$ & $1.61 \pm 0.09$ \\
\hline Children strain* & $1.79 \pm 0.08$ & $1.90 \pm 0.03$ & $1.86 \pm 0.03$ & $1.93 \pm 0.05$ & $1.70 \pm 0.06$ \\
\hline Role strain composite* & $1.89 \pm 0.05$ & $1.91 \pm 0.02$ & $1.98 \pm 0.02$ & $1.95 \pm 0.03$ & $1.89 \pm 0.04$ \\
\hline \multicolumn{6}{|l|}{ Hassles and Uplifts } \\
\hline Hassles & $0.51 \pm 0.06$ & $0.55 \pm 0.02$ & $0.50 \pm 0.02$ & $0.59 \pm 0.04$ & $0.50 \pm 0.05$ \\
\hline Health hassles & $0.62 \pm 0.09$ & $0.64 \pm 0.03$ & $0.57 \pm 0.03$ & $0.66 \pm 0.06$ & $0.60 \pm 0.07$ \\
\hline Uplifts & $0.84 \pm 0.07$ & $0.84 \pm 0.03$ & $0.86 \pm 0.03$ & $0.89 \pm 0.05$ & $0.89 \pm 0.06$ \\
\hline Health uplifts & $1.12 \pm 0.12$ & $1.14 \pm 0.04$ & $1.09 \pm 0.05$ & $1.05 \pm 0.08$ & $1.13 \pm 0.10$ \\
\hline \multicolumn{6}{|l|}{ Brief Symptom Inventory } \\
\hline Anxiety & $0.38 \pm 0.07$ & $0.51 \pm 0.02$ & $0.46 \pm 0.03$ & $0.42 \pm 0.05$ & $0.52 \pm 0.05$ \\
\hline Somatization & $0.25 \pm 0.05$ & $0.32 \pm 0.02$ & $0.28 \pm 0.02$ & $0.28 \pm 0.03$ & $0.28 \pm 0.04$ \\
\hline Interpersonal sensitivity & $0.64 \pm 0.08$ & $0.56 \pm 0.03$ & $0.49 \pm 0.03$ & $0.44 \pm 0.05$ & $0.55 \pm 0.06$ \\
\hline Psychoticism & $0.25 \pm 0.06$ & $0.31 \pm 0.02$ & $0.29 \pm 0.02$ & $0.27 \pm 0.04$ & $0.32 \pm 0.04$ \\
\hline Paranoid ideation & $0.57 \pm 0.08$ & $0.55 \pm 0.03$ & $0.52 \pm 0.03$ & $0.50 \pm 0.05$ & $0.56 \pm 0.06$ \\
\hline Depression & $0.30 \pm 0.08$ & $0.47 \pm 0.03$ & $0.44 \pm 0.03$ & $0.46 \pm 0.05$ & $0.46 \pm 0.06$ \\
\hline Hostility & $0.37 \pm 0.06$ & $0.44 \pm 0.02$ & $0.43 \pm 0.02$ & $0.49 \pm 0.04$ & $0.48 \pm 0.05$ \\
\hline Phobic anxiety & $0.16 \pm 0.05$ & $0.18 \pm 0.02$ & $0.18 \pm 0.02$ & $0.16 \pm 0.03$ & $0.19 \pm 0.04$ \\
\hline Obsessive-compulsive & $0.78 \pm 0.08$ & $0.77 \pm 0.03$ & $0.70 \pm 0.03$ & $0.62 \pm 0.05$ & $0.72 \pm 0.06$ \\
\hline \multicolumn{6}{|l|}{ Coping } \\
\hline Problem-focused coping ${ }^{*}$ & $13.27 \pm 0.37$ & $13.52 \pm 0.13$ & $12.97 \pm 0.14$ & $13.31 \pm 0.25$ & $12.78 \pm 0.29$ \\
\hline Emotion-focused coping ${ }^{*}$ & $11.92 \pm 0.30$ & $12.34 \pm 0.11$ & $11.87 \pm 0.12$ & $11.90 \pm 0.20$ & $11.76 \pm 0.24$ \\
\hline Less effective strategies & $5.92 \pm 0.17$ & $6.09 \pm 0.06$ & $5.85 \pm 0.06$ & $6.06 \pm 0.11$ & $5.86 \pm 0.13$ \\
\hline
\end{tabular}

* Statistically significant differences in mean psychosocial scores between various severities of attachment loss, $P \leq 0.05$, ANCOVA.

and financial strain $(P=0.006$, adjusted for multiple comparisons). Post hoc tests indicated that subjects with moderate CAL had a mean financial strain score of 1.94. This is compared to subjects with low levels of alveolar crestal height loss, who had a mean financial strain score of 1.66. Furthermore, those with high financial strain and severe CAL had a mean financial strain score of $1.98(P \leq 0.008)$. Healthy subjects, defined by their low levels of $\mathrm{ACH}$, also had significantly lower financial strain scores than those in low and moderate ACH groups, $P \leq 0.009$. This trend of differences was reversed for the scores of children strain and the strain of being single for both CAL and $\mathrm{ACH}$.
Regardless of the styles of coping be-havior, periodontally healthy individuals seemed to have higher coping scores than others in groups showing greater attachment or alveolar bone loss. Although tests using contrast weights for linear trends did not show a significant relationship, subjects with low levels of CAL had significantly higher mean problem-focused coping scores $(13.52 \pm 0.13)$ than those with moderate or severe CAL $(12.97 \pm 0.014,12.78 \pm 0.29$, respectively). Similar results were also found for the emotionfocused coping scores. These differences were also observed when alveolar crestal height was used as the measure of periodontal disease. Healthy subjects seem- 
Table 6.

\section{Adjusted Psychosocial Scores (Mean \pm SE) by Severity of Alveolar Bone Loss}

\begin{tabular}{|c|c|c|c|c|}
\hline \multirow[t]{2}{*}{ Psychological Scale } & \multicolumn{4}{|c|}{ Alveolar Bone Loss } \\
\hline & Healthy & Low & Moderate & Severe \\
\hline \multicolumn{5}{|l|}{ Life Events } \\
\hline Number of events & $2.81 \pm 0.13$ & $2.47 \pm 0.14$ & $2.50 \pm 0.18$ & $2.18 \pm 0.20$ \\
\hline Control ratings & $0.25 \pm 0.01$ & $0.24 \pm 0.01$ & $0.24 \pm 0.01$ & $0.24 \pm 0.02$ \\
\hline Impact ratings & $0.23 \pm 0.01$ & $0.22 \pm 0.01$ & $0.23 \pm 0.01$ & $0.22 \pm 0.01$ \\
\hline \multicolumn{5}{|l|}{ Role Strains } \\
\hline Job strain & $2.12 \pm 0.02$ & $2.10 \pm 0.03$ & $2.09 \pm 0.04$ & $2.19 \pm 0.04$ \\
\hline Financial strain* & $1.80 \pm 0.04$ & $1.90 \pm 0.04$ & $1.98 \pm 0.05$ & $1.99 \pm 0.06$ \\
\hline Spouse strain & $1.91 \pm 0.04$ & $1.93 \pm 0.04$ & $1.94 \pm 0.05$ & $1.88 \pm 0.06$ \\
\hline Being single strain* & $1.91 \pm 0.05$ & $1.80 \pm 0.05$ & $1.80 \pm 0.06$ & $1.63 \pm 0.07$ \\
\hline Children strain & $1.88 \pm 0.03$ & $1.84 \pm 0.03$ & $1.86 \pm 0.04$ & $1.88 \pm 0.04$ \\
\hline Role strain composite & $1.93 \pm 0.02$ & $1.93 \pm 0.02$ & $1.97 \pm 0.03$ & $1.94 \pm 0.03$ \\
\hline \multicolumn{5}{|l|}{ Hassles and Uplifts } \\
\hline Hassles & $0.58 \pm 0.02$ & $0.48 \pm 0.02$ & $0.54 \pm 0.03$ & $0.51 \pm 0.04$ \\
\hline Health hassles & $0.68 \pm 0.04$ & $0.55 \pm 0.04$ & $0.61 \pm 0.05$ & $0.59 \pm 0.06$ \\
\hline Uplifts & $0.84 \pm 0.03$ & $0.82 \pm 0.03$ & $0.95 \pm 0.04$ & $0.89 \pm 0.05$ \\
\hline Health uplifts & $1.09 \pm 0.05$ & $1.07 \pm 0.05$ & $1.21 \pm 0.07$ & $1.14 \pm 0.08$ \\
\hline \multicolumn{5}{|l|}{ Brief Symptom Inventory } \\
\hline Anxiety & $0.49 \pm 0.03$ & $0.49 \pm 0.03$ & $0.41 \pm 0.04$ & $0.51 \pm 0.04$ \\
\hline Somatization & $0.32 \pm 0.02$ & $0.31 \pm 0.02$ & $0.23 \pm 0.03$ & $0.30 \pm 0.03$ \\
\hline Interpersonal sensitivity & $0.56 \pm 0.03$ & $0.49 \pm 0.03$ & $0.46 \pm 0.04$ & $0.53 \pm 0.05$ \\
\hline Psychoticism & $0.29 \pm 0.02$ & $0.31 \pm 0.02$ & $0.26 \pm 0.03$ & $0.33 \pm 0.03$ \\
\hline Paranoid ideation & $0.57 \pm 0.03$ & $0.55 \pm 0.03$ & $0.47 \pm 0.04$ & $0.52 \pm 0.05$ \\
\hline Depression & $0.44 \pm 0.03$ & $0.45 \pm 0.03$ & $0.40 \pm 0.04$ & $0.49 \pm 0.05$ \\
\hline Hostility & $0.45 \pm 0.02$ & $0.43 \pm 0.03$ & $0.41 \pm 0.03$ & $0.48 \pm 0.04$ \\
\hline Phobic anxiety & $0.17 \pm 0.02$ & $0.17 \pm 0.02$ & $0.16 \pm 0.02$ & $0.20 \pm 0.03$ \\
\hline Obsessive-compulsive & $0.78 \pm 0.03$ & $0.71 \pm 0.03$ & $0.64 \pm 0.04$ & $0.68 \pm 0.05$ \\
\hline \multicolumn{5}{|l|}{ Coping } \\
\hline Problem-focused coping & $13.32 \pm 0.15$ & $13.03 \pm 0.16$ & $13.44 \pm 0.21$ & $13.00 \pm 0.23$ \\
\hline Emotion-focused coping & $12.23 \pm 0.13$ & $11.96 \pm 0.13$ & $11.92 \pm 0.17$ & $11.87 \pm 0.19$ \\
\hline Less effective strategies & $6.07 \pm 0.07$ & $5.91 \pm 0.07$ & $5.86 \pm 0.09$ & $5.93 \pm 0.10$ \\
\hline
\end{tabular}

* Statistically significant differences in mean psychosocial scores between various severities of attachment loss, $P \leq 0.05$, ANCOVA.

ed to have a greater number of life events, more control of what happened to them, but a greater degree of negative impact. How-ever, the differences were not statistically significant when compared to other groups when either clinical attachment level or alveolar crestal height were used as measures of periodontal disease.

Subjects at all levels of CAL and ACH had similar psychosocial scores in all of the subscales of Hassles and Uplifts. Although subjects with severe CAL exhibited higher scores than healthy individuals in anxiety, somatization, psychoticism, depression, hostility, and phobic anxiety of the BSI, the adjusted mean differ- ences were not statistically significant (Table 5). Similar non-significant differences for Hassles and Uplifts and BSI were also recorded when $\mathrm{ACH}$ was measured, and are displayed in Table 6.

Results of the stepwise ordinal logistic regression analysis considering psychosocial variables and possible confounding or co-risk factors are shown in Table 7 . From this analysis it can be seen that an increase in clinical attachment loss was significantly associated with financial strain $(\mathrm{OR}=1.37,95 \%$ confidence interval, $\mathrm{CI}$ $=1.04$ to 1.81$)$ and depression (OR = $1.51,95 \% \mathrm{CI}=1.02$ to 2.22). Less attachment loss was associated with strain of being single $(\mathrm{OR}=$ $0.44,95 \% \mathrm{CI}=0.28$ to $0.68)$. Other variables that were significantly associated with increased severity of attachment loss were age, gender (male), smoking, diabetes mellitus, depression, and the subgingival microorganisms $B$. forsythus and $P$. gingivalis (Table 7 ). Variables that appear to be associated with less severe attachment loss include education (higher), Capnocytophaga species, allergic history, and coping (Table 7).

Stratifying the subjects according to their coping behavior allowed us to assess the risk differential of different disease levels between individuals with "high" and "low" emotion-focused and problem-focused coping behaviors while controlling for age, gender, and smoking (Tables 8 and 9). Subjects with high emotionfocused coping and more financial strain had a greater risk of having more severe attachment loss $(\mathrm{OR}=2.24$, 
Table 7.

Results of Stepwise Ordinal Logistic Regression Analysis on Psychosocial Variables, Socioeconomic Status, Systemic Diseases, Occupational Hazards, Smoking, and Microflora When Adjusted for Decade, as Related to Periodontal Attachment Loss

\begin{tabular}{|c|c|c|}
\hline Variables & $\begin{array}{l}\text { Estimated Odds } \\
\text { Ratio* }\end{array}$ & $\begin{array}{l}\text { 95\% Confidence } \\
\text { Interval }\end{array}$ \\
\hline Aged 65-74 & 11.21 & $(7.39,17.02)$ \\
\hline Heavy smoker & 4.74 & $(3.34,6.73)$ \\
\hline Aged 55-64 & 4.18 & $(2.80,6.24)$ \\
\hline Moderate smoker & 3.08 & $(2.17,4.37)$ \\
\hline Aged 45-54 & 3.07 & $(2.08,4.54)$ \\
\hline B. forsythus & 2.51 & $(1.93,3.27)$ \\
\hline Diabetes & 2.36 & $(1.28,4.35)$ \\
\hline Light smoker & 2.20 & $(1.59,3.05)$ \\
\hline P. gingivalis & 1.63 & $(1.16,2.29)$ \\
\hline Aged 35-44 & 1.53 & $(1.05,2.23)$ \\
\hline Depression & 1.51 & $(1.02,2.22)$ \\
\hline Financial strain & 1.37 & $(1.04,1.81)$ \\
\hline Gender (male) & 1.33 & $(1.03,1.70)$ \\
\hline Emotion-focused coping & 0.71 & $(0.53,0.96)$ \\
\hline Allergy & 0.70 & $(0.54,0.92)$ \\
\hline Capnocytophaga spp. & 0.68 & $(0.49,0.94)$ \\
\hline Education & 0.67 & $(0.52,0.85)$ \\
\hline Strain of being single & 0.44 & $(0.28,0.68)$ \\
\hline
\end{tabular}

* Statistically significant with $P<0.05$.

$95 \% \mathrm{CI}=1.15$ to 4.38$)$ and alveolar bone loss (OR = $1.91,95 \% \mathrm{CI}=1.15$ to 3.17 ) than those with less financial strain. This relationship remained strong even after adjustments were made for varying levels of previous dental care. Similar results were found among the low problem-focused copers for CAL (OR $=2.21,95 \% \mathrm{CI}=$ 1.11 to 4.38$)$ and $\mathrm{ACH}(\mathrm{OR}=2.12,95 \% \mathrm{CI}=1.28$ to $3.51)$. On the other hand, those financially strained subjects with high levels of problem-focused coping had levels of periodontal disease comparable to subjects who had little or no financial strain. These results for subjects with high levels of financial strain are graphically depicted in Figure 1. It can be seen that the risk for periodontal disease for all subjects is greater in those

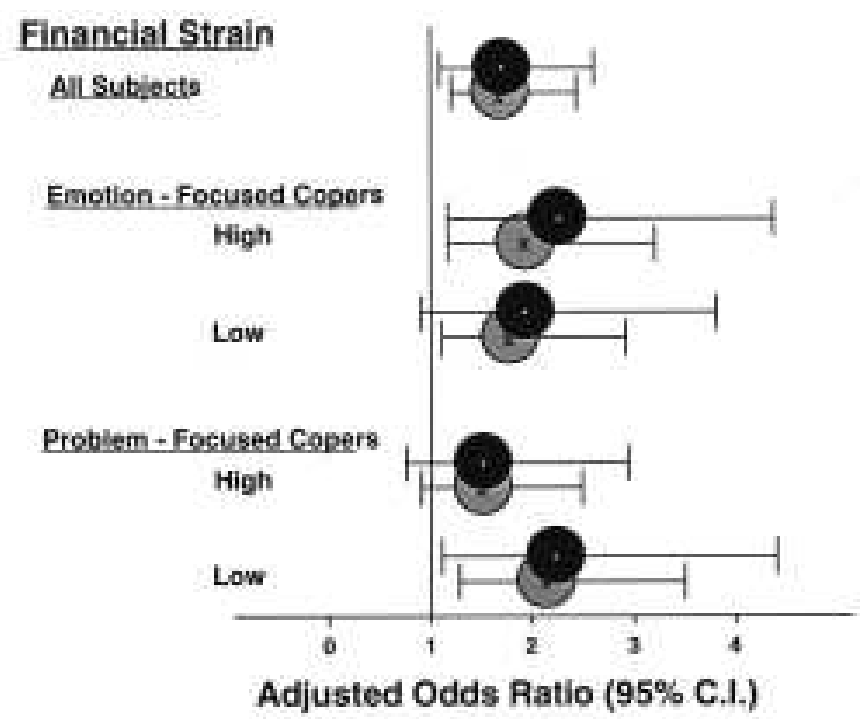

\section{Q Periodontal Attachment Loss \\ (メ) Alveolar Bone Loss}

Figure I.

Association between severity of periodontal attachment loss and alveolar bone loss in those reporting financial strain and different coping behaviors, adjusting for age, gender and smoking.

with high levels of financial strain; however, those scoring high on emotion-focused coping (poor coping) are at even greater risk for periodontal disease. In contrast, those subjects with high levels of financial strain who report high levels of problem-focused coping (good coping) are at no more risk for periodontal disease than those who report little or no financial strain.

\section{DISCUSSION}

Studies relating psychosocial factors to general health status of an individual have been conducted for many years. ${ }^{39-41}$ However, most of those studies involved a small number of subjects, and only a few reported the relationship between psychosocial factors and oral health, in particular periodontal disease. ${ }^{24-26,42}$ The purpose of the present study was to investigate the moderating effects of psychosocial factors on periodontal health in a large survey study in which potential confounding factors such as age, gender, smoking, general health, and dental care could be controlled. We found that stress, revealed as financial strain, and depression were associated with greater levels of periodontal disease assessed as higher levels of clinical attachment loss or as high levels of alveolar bone loss, 2 independently measured but correlated measures of destructive periodontal disease. We also found that those individuals who possessed good coping behaviors, even when under financial strain, exhibited no more periodontal disease than those individuals not under financial strain. 
Table 8.

\section{Association Between Daily Strains Score and Severity of Attachment Loss}

\begin{tabular}{|c|c|c|}
\hline \multirow[t]{2}{*}{ Attribute } & \multicolumn{2}{|c|}{ Attachment Loss } \\
\hline & Odds Ratio* & 95\% C.I. \\
\hline \multicolumn{3}{|c|}{ Emotion-Focused Copers (high) } \\
\hline Job strain & 1.30 & $0.58-2.88$ \\
\hline Financial strain & $2.24 t^{\dagger}$ & $1.15-4.38$ \\
\hline Spouse strain & 1.06 & $0.46-2.42$ \\
\hline Being single strain & 0.60 & $0.23-1.56$ \\
\hline Children strain & 0.59 & $0.27-1.30$ \\
\hline Role strain & 1.29 & $0.50-3.33$ \\
\hline \multicolumn{3}{|c|}{ Emotion-Focused Copers (low) } \\
\hline Job strain & 0.56 & $0.27-1.16$ \\
\hline Financial strain & 1.91 & $0.97-3.76$ \\
\hline Spouse strain & 0.88 & $0.43-1.80$ \\
\hline Being single strain & $0.35^{\dagger}$ & $0.13-0.91$ \\
\hline Children strain & 0.96 & $0.45-2.09$ \\
\hline Role strain & 1.52 & $0.68-3.39$ \\
\hline \multicolumn{3}{|c|}{ Problem-Focused Copers (high) } \\
\hline Job strain & 1.22 & $0.53-2.78$ \\
\hline Financial strain & 1.49 & $0.76-2.92$ \\
\hline Spouse strain & 1.06 & $0.45-2.49$ \\
\hline Being single strain & 0.53 & $0.19-1.45$ \\
\hline Children strain & 0.53 & $0.24-1.19$ \\
\hline Role strain & 1.05 & $0.43-2.62$ \\
\hline \multicolumn{3}{|c|}{ Problem-Focused Copers (low) } \\
\hline Job strain & 0.63 & $0.31-1.27$ \\
\hline Financial strain & $2.21^{\dagger}$ & I.II- 4.38 \\
\hline Spouse strain & 0.96 & $0.48-1.93$ \\
\hline Being single strain & 0.51 & $0.21-1.24$ \\
\hline Children strain & 1.10 & $0.52-2.30$ \\
\hline Role strain & 1.29 & $0.56-2.98$ \\
\hline
\end{tabular}

* All models were adjusted for decade, gender, and levels of smoking.

$\dagger$ Statistically significant $(P \leq 0.05)$.

(For AL: Severe $\&$ High groups were compared to Healthy $\&$ Low groups)

Since these conclusions are based on self-reported psychosocial traits, the goodness of fit of the collected data of our study population to the hypothetical factor structures of the psychosocial instruments used was important to establish. Cronbach coefficients of all subscales of the instruments were high (Tables 1 through 4). In fact, the lowest Cronbach recorded (0.89) was from the health Uplifts subscale. These high correlations indicate that items being used and constructed from the hypothetical universe of items of each scale measured a common entity and had reasonably good reliability when applied to our sample of individuals.

Results from the factor analysis model on 3 instruments, Daily Strain, BSI, and Coping, were further supportive of the reliability coefficients. It was difficult to
Table 9.

\section{Association Between Daily Strains Score and Severity of Alveolar Bone Loss}

\begin{tabular}{|c|c|c|}
\hline \multirow[t]{2}{*}{ Attribute } & \multicolumn{2}{|c|}{ Alveolar Bone Loss } \\
\hline & Odds Ratio* & $95 \%$ C.I. \\
\hline \multicolumn{3}{|c|}{ Emotion-Focused Copers (high) } \\
\hline Job strain & 1.02 & $0.56-1.83$ \\
\hline Financial strain & $1.91 \dagger$ & $1.15-3.17$ \\
\hline Spouse strain & 0.88 & $0.47-1.62$ \\
\hline Being single strain & 0.50 & $0.24-1.03$ \\
\hline Children strain & 1.26 & $0.71-2.26$ \\
\hline Role strain & 1.01 & $0.51-1.99$ \\
\hline \multicolumn{3}{|c|}{ Emotion-Focused Copers (low) } \\
\hline Job strain & 1.08 & $0.63-1.86$ \\
\hline Financial strain & $1.76^{\dagger}$ & $1.06-2.9 \mid$ \\
\hline Spouse strain & 0.90 & $0.52-1.54$ \\
\hline Being single strain & 0.76 & $0.38-|.5|$ \\
\hline Children strain & 1.43 & $0.81-2.52$ \\
\hline Role strain & 0.79 & $0.43-1.44$ \\
\hline \multicolumn{3}{|c|}{ Problem-Focused Copers (high) } \\
\hline Job strain & 1.04 & $0.56-1.91$ \\
\hline Financial strain & 1.49 & $0.89-2.47$ \\
\hline Spouse strain & 0.82 & $0.44-1.53$ \\
\hline Being single strain & 0.54 & $0.25-1.18$ \\
\hline Children strain & 1.54 & $0.85-2.78$ \\
\hline Role strain & 1.02 & $0.52-2.02$ \\
\hline \multicolumn{3}{|c|}{ Problem-Focused Copers (low) } \\
\hline Job strain & 1.18 & $0.69-2.00$ \\
\hline Financial strain & $2.12^{\dagger}$ & $|.28-3.5|$ \\
\hline Spouse strain & 1.03 & $0.60-1.76$ \\
\hline Being single strain & 0.84 & $0.44-1.59$ \\
\hline Children strain & 1.33 & $0.77-2.30$ \\
\hline Role strain & 0.67 & $0.36-1.23$ \\
\hline
\end{tabular}

* Adjusted for decade, gender, and levels of smoking.

$\dagger$ Statistically significant $(P \leq 0.05)$.

(For ABL: Severe \& Moderate groups were compared to Healthy \& Low groups)

reproduce the exact factor structures of the original instruments for 2 reasons: first, we did not utilize all of the items from the original instruments, and second, some instruments, the BSI for example, were developed and designed primarily to reflect the psychological symptom patterns of psychiatric and medical patients as compared to our "healthy" population being studied. A factor analysis by Angst et al. ${ }^{43}$ on the symptom check-list (SCL) results of 1,162 non-clinical young men displayed similar difficulties in replicating some of the factor structures. Also in the studies of Hoffmann and Overall, ${ }^{44}$ Clark and Friedman, ${ }^{45}$ and Holcomb et al., ${ }^{46}$ the factor "anxiety" was suggested to be included in the factor "phobic anxiety." Cyr et al. ${ }^{47}$ and Alvir et al. ${ }^{48}$ even suggested that the individual dimensions are 
highly correlated with one another and that the results are primarily a measure of a "General Distress Index." Nevertheless, the high Cronbach alphas obtained from the 9 dimensions were all more than 0.92 (Table 3) and thus indicated that the 9 dimensions we used were quite reliable. Similar factor loading structure and even higher Cronbach alphas were obtained from items comparing each of the 3 coping dimensions. We have further corroborated the results of the psychosocial scales by measuring salivary cortisol levels in the same subjects. 49

The lack of significant association between job strain and periodontal health in our study, measured by attachment and alveolar bone loss, may be explained by the presence of some other uncontrolled extraneous variables which may affect the job strain scores. It may also depend on how a person handles and copes with the job strain he/she encounters because stress from a job is not the same experience for everyone; or it may depend on how much social support, if any, is available from families, friends, and coworkers, which could lessen the potential stress. Another possible explanation for the lack of significant association is that the subject's responses may reflect a temporary or recent experience, while periodontal disease is a chronic event.

Subjects with more severe attachment loss did have significantly more financial strain scores than healthy individuals $(P=0.01)$. Subjects with severe, high, and moderate levels of attachment loss had mean financial strain scores of 1.98, 1.98, and 1.94, respectively, compared to 1.66 recorded from the healthy subjects. This significant difference was also found when comparing the healthy to moderate and severe bone loss groups.

Results from our multivariate analysis also demonstrate the significant association of financial strain with periodontal disease, which remained after controlling for the well-established risk factors of age, gender, and smoking. The relationship of greater financial strain associated with greater levels of periodontal disease, as measured by attachment loss or alveolar bone loss, is interesting in that this measure is one of the scales on the measures of stress, i.e., Daily Strains, which measures chronic stressors associated with the central roles people occupy in life. This particular measure evaluates the role as financial manager. The 9 questions asked assess chronic, long-term financial status rather than transient, acute financial stress. Examples of these questions are: At the present time, are you able to afford a home that is large enough? Can you afford furniture that needs to be replaced? Do you have difficulty in meeting monthly payments of your family bills? In general, how do your family finances work out at the end of the month? Do you usually end up with money left over, not enough to make ends meet, or just enough to make ends meet? How often is it that you don't have enough money to afford the kind of food, clothing, med- ical care, or leisure activities you and your family should need or want? These questions likely evoke a response representative of chronic, long-term daily strain which is likely to lead to long-term, chronic stress. This chronic stress then may lead to adverse effects on immune response which could, in turn, reduce resistance to periodontal disease. It is also possible that those under financial strain may visit the dentist less frequently, and thus have poorer dental care and more disease. When we adjusted for visits to the dentist, however, those with high financial strain and poor coping still had high levels of periodontal disease. These results suggest that stress and inadequate coping, and not poor dental care which might result from stress, are associated with periodontal disease.

Other interesting relationships were found between severity of periodontal disease and financial strain for "high" and "low" emotion-focused coping behaviors. Those who had financial strain and who also reported they were "high" emotion-focused copers or "low" problem-focused copers, both likely inadequate forms of coping, had an even higher risk for more severe periodontal disease. On the other hand, those who have high levels of problem-based coping, interpreted as good or adequate coping, had no more periodontal destruction than subjects who were not under financial stress. In other words, adequate coping with the chronic stress resulted in little or no effect of the stress on periodontal status.

Coping is the response of subjects in an attempt to control, reduce, or avoid the negative and unpleasant effects of stress. Subjects with financial strain who used emotion-focused coping strategies had even more periodontal disease. These emotion-focused coping strategies include strategies such as consuming alcohol or drugs to make himself/herself feel better; admitting that he/she can't deal with it and quit trying; and pretending that the problem hasn't really happened. These emotion-focused strategies are "avoidance," and not likely to be effective in dealing with stress and are associated with low levels of well-being. Problem-focused coping, on the other hand, is associated with high levels of wellbeing. ${ }^{50}$ This may also explain why those with high problem-focused coping behavior have less risk of periodontal disease, since they not only "make a plan of action," as our psychosocial questionnaire asked, but also "take additional action to try to get rid of the problem." Although emotion-focused coping, which included seeking social support, has some positive effects (e.g., on both appetite and nutrient intake which may, in turn, lead to good health), some researchers caution that companionship may also operate as a double-edged sword. Companionship can be both a buffer between poor appetite and dietary intake, and an enhancement of the negative impact of financial stress on appetite. ${ }^{51}$ 
Subjects who were single had less risk for periodontal disease in our study. Being single may also help to foster independence and hardiness, which will increase and strengthen in the face of challenge. On the other hand, those who were married also exhibited some forms of stress which could have negative or positive impacts on their periodontal health. Marcenes and Sheiham ${ }^{24}$ postulated that those who were dissatisfied with their marriages were more likely to be in poorer physical and psychological health than those who were single, widowed, or divorced. Our results did not show a negative impact of spouse strain on periodontal health, perhaps because it may depend on the quality of marriage, i.e., whether or not an individual is satisfied with his/her marriage. If the marriage is not happy, anxiety and other mental symptoms may develop which will have direct or indirect effects on somatic health. Additional analysis including only single individuals in the sample showed that there was no significant relationship between the strain of being single and periodontal disease. Further studies of the effects of being single, and the effects of differing qualities of marriages, may help explain our initial finding related to periodontal disease.

Compared to the healthy subjects, there were trends of greater psychologic distress, measured by the Brief Symptom Inventory, among those with more severe attachment or alveolar bone loss. Greater distress was observed on each of the anxiety, somatization, psychoticism, depression, hostility, and phobic anxiety subscales for those with more periodontal disease. However, only depression was statistically significantly related to periodontal disease after adjusting for age, gender and smoking $(\mathrm{OR}=1.51,95 \% \mathrm{CI}=1.02$ to 2.22). These results echo the findings of Stewart et al., ${ }^{52}$ who found that perimenopausal women had significantly greater distress than menopausal women. Kawachi et al. ${ }^{53}$ and Hayward ${ }^{54}$ used a similar selfrated psychological scale which suggested that phobic anxiety increased the risk of sudden cardiac death. These 6 dimensions composed a wide range of symptoms which may reflect mood disorders, life events encountered and impacts on them, and possible role changes of subjects. Distress might also result from physical symptoms secondary to hormonal changes, or it might lead to eating disorders, tobacco smoking, drug addiction, increased alcohol consumption, decreased physical activity, and poor self care, and thus indirectly contribute to the susceptibility of various diseases, including periodontal disease. Longitudinal studies relating the temporal relationship of distress, such as depression, to periodontal disease onset and progression are necessary to establish whether depression is truly a risk factor for periodontal disease, or whether depression results, in part, from poor health associated with periodontal disease.
There are studies that support the psychophysiological reactivity model of hostility and health. A study by Scherwitz et al. ${ }^{55}$ suggested that more hostile young adults are more likely to smoke tobacco and marijuana, and drink more alcohol. They also experienced more undesirable life events and less social support. Therefore, with less social support and increasing daily stress, they may have coped with these by eating and smoking more. In our study population, smoking was found to be one of the important risk indicators for periodontal disease, and further studies are needed to determine if hostility may contribute to this relationship.

The lack of significance of BSI scores, other than depression, might be the result of some physical, psychological, and/or other possible factors, such as medications being taken or hormone replacement therapy by women, all of which could affect mental health. Progestins, for example, have previously been shown to affect the mood of individuals. ${ }^{56}$ As hormones are helpful in creating a sense of well-being, any psychological affect may secondarily result from better physical functioning. When periodontally healthy individuals were compared with those with severe periodontal disease (Tables 5 and 6), there was a trend to an inverse relationship relating the severity of periodontal disease and interpersonal sensitivity, paranoid ideation, and obsessive-compulsive behavior which may result from differences in oral hygiene. However, this trend was not statistically significant. There were proportionally more subjects in the healthy attachment loss group who had zero scores in interpersonal sensitivity, paranoid ideation, and obsessive-compulsive behavior who did not have a dental cleaning in the past before visiting our research clinic (76\%, 92\%, and 90\%, respectively) as compared to those with higher psychological scores in the same group $(66 \%, 64 \%$, and $65 \%$, respectively), and those in the severe attachment loss group (49\%, 50\%, and $46 \%)$. Similar differences in the proportion of dental cleaning also existed when the severe level of alveolar bone loss was considered.

We also showed that those with better coping behaviors, i.e., those with high levels of problem-focused coping, had less periodontal tissue destruction, even though they reported high levels of financial strain. Conversely, those with high levels of financial strain who utilized poor coping strategies, evidenced as emotion-focused coping, were found to have even more severe periodontal destruction. We also found that those individuals with more severe levels of periodontal tissue destruction also reported depression, a measure of distress. These relationships of financial strain, coping behaviors, and distress were not simply related to age, gender, smoking or other confounding factors, as the relationship existed after adjustment for these factors. Hence, we feel that the associations between distress (depression) and financial stress as modified by 
coping with varying levels of periodontal disease are significant and may be related to the effects of stress, such as the well-known effects of stress on the immune system, increasing susceptibility to periodontal disease.

The relationship of the severity of periodontal disease assessed by mean attachment loss and alveolar bone loss to the total number of life events, regardless of negative or positive events, was measured. Subjects with less clinical attachment loss or alveolar bone loss had experienced a significantly higher total number of life events than those with more severe attachment loss $(P$ $\leq 0.05$ ); however, subjects with severe periodontal disease seemed to have more control and less negative impact on their lives from these life events. Our result was not unexpected since the life events in our analysis comprised both the negative and positive events. Positive events in our sample may be more frequent than negative events and, thus, effects from the negative events on the periodontal health might have been counterbalanced by those "happy" events. Previous studies have shown conflicting relationships between life events and the state of health. Forsén, 57 in a breast cancer study, found that cancer patients had significantly more life events than the controls. Results from a herpes zoster study also proved that case subjects experienced significantly more negative life events than those in the control groups. ${ }^{58}$ However, most of the positive relationships found involved stressful or negative life events, and other factors were not controlled in the analysis. Tennant et al. ${ }^{59}$ found no evidence that recent acute stressful events or chronic difficulties were independently related to coronary artery atherosclerosis when potential confounding variables such as gender were controlled. Recent stressful life events also did not differ between the studied groups in a juvenile arthritis study by Vandvik et al. ${ }^{60}$ and were not associated with severity of disease.

Daily Uplifts and Hassles made little contribution to periodontal health in our population. Hassles are considered as those minor but repeated or chronic daily stressors which, in some studies, had been defined as salient and harmful to an individual's well-being. However, the degree of harm to somatic health may depend on how an individual adjusts oneself to cope with and control these daily stressors. High control of hassles may attenuate or buffer the negative effects on periodontal disease, as might controllable uplifts. It may also depend on the effects on periodontal health of other potential confounders. Weinberger et al. ${ }^{61}$ suggested that a subject's cultural, economic, and social background had to be considered when measuring effects of hassles. Some studies also suggested that daily hassles should be assessed along with life events in order to have a full understanding and practical prediction of health outcomes. ${ }^{39}$ Another factor which may have affected our results is that the Hassles and Uplifts scale elicits information about events occurring only on the day of the visit. Given the chronic nature of periodontal disease and the proximal measures of stress of daily hassles, the negative results from the analysis are not surprising.

Of the 6 dimensions of Daily Strains/Stress, job-, spouse- and children-associated strains did not have consistent linear relationships with dental disease. The strain of being single had an inverse relationship with dental disease; however, financial strain showed a positive relationship with CAL and $\mathrm{ACH}$. Since stress is associated with a wide range of health problems, it is logical to speculate that stress may significantly affect one's well-being. In regard to oral health, there has been a report that stress can cause salivary changes. ${ }^{23}$ The continual production of highly viscous, low-volume, acidic, glycoprotein-rich saliva could lead to increased adherence and generation of plaque-forming bacteria on tooth surfaces which, in turn, could facilitate the development of carious lesions in the presence of sucrose. Although the differences in job strain scores (Tables 5 and 6) relating healthy subjects to those with various levels of periodontal disease assessed by attachment and alveolar bone loss are not consistent with other published studies in terms of significance, they are consistent with the results reported by Marcenes and Sheiham, ${ }^{24}$ who found that oral health status was associated with work stress. Sutton ${ }^{62}$ postulated that stress would reduce the efficacy of the immune system which, in turn, would decrease the defense against bacterial attack, permitting the development of acute dental caries. This theory also can be applied to periodontal disease. For example, in our results, those with severe periodontal disease showed a higher job strain score than those with healthy periodontal tissues. Gardell ${ }^{63}$ suggested that high mental demands, excessive work and time pressure, understimulation, underutilization of skills, and lack of opportunity to learn new ways of doing things are important job stressors; these were included in the self-reported job-related questions asked of our subjects. Job stress and subsequent illness, which in our study is periodontal disease, occur when a subject's ability to deal with and meet the intensive psychological demands of work is impaired. A previous study also showed that an increase in probing depth was significantly predicted by job stress. ${ }^{26}$

Although not all of the psychosocial factors we measured were related with the disease, the results were, in part, supportive of previous suggestions by other investigators. Periodontal disease is a long-term health outcome and, therefore, it is likely that a chronic pattern of adverse psychosocial effects is required to have a measurable disease impact. Also, since our results are based on cross-sectional data, it is necessary to inject a 
note of caution that further research is needed in order to understand the scope and mechanisms of psychosocial effects on periodontal health, and to see if they indeed are true risk factors for periodontal disease. We have recently completed a longitudinal study on a subgroup of these 1,426 individuals, and hopefully this analysis will help us to review the mechanisms of these effects. If a specific domain of psychosocial factors can be identified as associated with poor periodontal outcomes, intervention measures including stress reduction may provide adjunctive approaches for preventing and treating periodontal disease.

\section{ACKNOWLEDGMENTS}

The authors appreciate the efforts of Drs. Maurizio Trevisan and James Marshall for their assistance with the analysis of the psychosocial data and its application to our population. We also appreciate the discussions with and preliminary analysis of a subset of these data by Drs. Mark Moss and James Beck regarding these studies. We appreciate the efforts of Drs. Lars Christersson, Sebastiano Andreana, and Ernest Hausmann for their assistance in assessing the patients in this epidemiologic study. This study was supported by USPHS grants DE04898, DE07034, and DE00158.

\section{REFERENCES}

1. Genco R, Löe H. The role of systemic conditions and disorders in periodontal disease. Periodontol 2000 1993;2:98-116.

2. Genco RJ. Current view of risk factors for periodontal diseases. J Periodontol 1996;67(Suppl.):1041-1049.

3. Pindborg J. Gingivitternes hypighed og arsager belyst ved unders $\varnothing$ gelase af 3600 soldater. Tandlaegebladet 1946;50:421.

4. Pindborg J. Tobacco and gingivitis. I. Statistical examination of the significance of tobacco in the development of ulceromembranous gingivitis and in the formation of calculus. J Dent Res 1947;26:261-264.

5. Frandsen A, Pindborg J. Tobacco and gingivitis. III. Difference in action of cigarette and pipe smoking. $J$ Dent Res 1949;28:264-265.

6. Herulf G. Om det marginale alveolarbenet hos ungdom i studiealderen - en röntgenstudie. Su Tandl T 1950;43:4282.

7. Mehta F. Prevalence of periodontal disease. 5. Epidemiology in an Indian child population in relation to their socio-economic status. Int Dent J 1956;6:31-40.

8. Lovdal A, Arno A, Waerhaug J. Incidence of clinical manifestations of periodontal disease in light of oral hygiene and calculus formation. J Am Dent Assoc 1958;56:21-33.

9. Schei O, Arno A, Lövdal A, Waerhaug J. Alveolar bone loss as a function of tobacco consumption. Acta Odontol Scand 1959;17:3-10.

10. Schei O, Waerhaug J, Lövdal A, Arno A. Alveolar bone loss as related to oral hygiene and age. $J$ Periodontol 1959;30:7-16.

11. Russell A. Geographical distribution and epidemiology of periodontal disease. (WHO/DH/33/34). Geneva: World Health Organization; 1960.
12. Miller A, Brunelle J, Carlos J, Brown L, Löe H. Oral health of United States adults. The National Survey of Oral Health in U.S. Employed Adults and Seniors: 19851986. National Findings (NIH Publication No. 87-2868). Bethesda: National Institutes of Health; 1987.

13. Bacic M, Plancak D, Granic M. CPITN assessment of periodontal disease in diabetic patients. $J$ Periodontol 1988;59:816-822.

14. Beck J, Koch G, Rozier R, Tudor G. Prevalence and risk indicators for periodontal attachment loss in a population of older community-dwelling blacks and whites. $J$ Periodontol 1990;61:521-528.

15. Emrich LJ, Shlossman M, Genco RJ. Periodontal disease in non-insulin-dependent diabetes mellitus. J Periodontol 1991;62:123-130.

16. Grossi SG, Zambon JJ, Ho AW, et al. Assessment of risk for periodontal disease. I. Risk indicators for attachment loss. J Periodontol 1994;65:260-267.

17. Grossi S, Dunford R, Reynolds H, Zambon J, Christersson L. Clinical and microbiological parameters in the diagnosis of severe periodontal disease in older adults. J Dent Res 1990;69(Spec. Issue):361(Abstr. 2021).

18. Grossi SG, Genco RJ, Machtei EE, et al. Assessment of risk for periodontal disease. II. Risk indicators for alveolar bone loss. J Periodontol 1995;66:23-29.

19. Beck JD, Koch GG, Zambon JJ, Genco RJ, Tudor GE. Evaluation of oral bacteria as risk indicators for periodontitis in older adults. J Periodontol 1992;63:9399.

20. Sandler HC. The influence of generalized diseases on clinical manifestations of periodontal disease. J Am Dent Assoc 1954;49:656-667.

21. Sandler HC. Prevalence of periodontal disease in a hospitalized population. J Dent Res 1960;39:439-449.

22. Shlossman M, Knowler W, Pettitt D, Genco R. Type 2 diabetes mellitus and periodontal disease. J Am Dent Assoc 1990; 121:532-536.

23. Morse DR, Schacterle GR, Furst L, et al. The effect of stress and meditation on salivary protein and bacteria: A review and pilot study. J Human Stress 1982;8(4):31-39.

24. Marcenes WS, Sheiham A. The relationship between work stress and oral health status. Soc Sci Med 1992; 35:1511-1520.

25. Green LW, Tryon WW, Marks B, Huryn J. Periodontal disease as a function of life events stress. J Human Stress 1986;12(1):32-36.

26. Freeman R, Goss S. Stress measures as predictors of periodontal disease - A preliminary communication. Community Dent Oral Epidemiol 1993;21:176-177.

27. Moss ME, Beck JD, Kaplan BH, et al. Exploratory casecontrol analysis of psychosocial factors and adult periodontitis. J Periodontol 1996;67:1060-1069.

28. Grossi SG, Dunford RG, Ho A, Koch G, Machtei EE, Genco RJ. Sources of error for periodontal probing measurements. J Periodont Res 1996;31:330-336.

29. Hausmann E, Allen K, Carpio L, Christersson L, Clerehugh V. Computerized methodology for detection of alveolar crestal bone loss from serial intra-oral radiographs. J Periodontol 1992;63:657-662.

30. Zambon J, Reynolds H, Chen P, et al. Rapid identification of periodontal pathogens in subgingival dental plaque: Comparison of indirect immunofluorescence microscopy with bacterial culture for detection of Bacteroides gingivalis. J Periodontol 1985;56(Suppl.):32-40.

31. Bonta C, Zambon J, Genco RJ, Neiders ME. Rapid 
identification of periodontal pathogens in subgingival dental plaque: Comparison of indirect immunofluorescence microscopy with bacterial culture for detection of Actinobacillus actinomycetemcomitans. $J$ Dent Res 1985;64:793-798.

32. Dohrenwend B, Krasnoff L, Askenasy A, Dohrenwend B. Exemplification of a method for scaling life events: The PERI life events scale. J Health Soc Behav 1978;19:205229.

33. Pearlin L, Schooler C. The structure of coping. J Health Soc Behav 1978;19:2-21.

34. Derogatis L, Spencer P. The Brief Symptom Inventory (BSI): Administration, Scoring and Procedures, Manual I. Towson, MD: Clinical Psychometric Research; 1982.

35. Carver C, Scheier M, Weintraub J. Assessing coping strategies: A theoretically based approach. J Personality Soc Psychol 1989;56:267-283.

36. Dohrenwend B, Krasnoff L, Askenasy A, Dohrenwend B. In: Goldberger L, Breznitz S, eds. Handbook of Stress: Theoretical and Clinical Aspects. New York: The Free Press; 1982:332.

37. Rummel RJ. Applied Factor Analysis. Chicago: Northwestern University Press; 1970.

38. Norusis MJ. SPSS Base System User's Guide: Reliability Analysis. Chicago: SPSS Inc.; 1990.

39. DeLongis A, Coyne JC, Dakof G, Folkman S, Lazarus RS. Relationship of daily hassles, uplifts, and major life events to health status. Health Psychol 1982;1:119-136.

40. Cohen LH, Simons RF, Rose SC, McGowan J, Zelson MF. Relationships among negative life events, physiological reactivity, and health symptomatology. J Human Stress 1986;12(4):142-148.

41. Cooper CL, Faragher EB. Psychosocial stress and breast cancer: The inter-relationship between stress events, coping strategies and personality. Psycholog Med 1993;23:653-662.

42. Linden G, Mullally B, Freeman R. Stress and the progression of periodontal disease. J Clin Periodontol 1996;23:675-680.

43. Angst J, Dobler-Mikila A, Binder J. The Zurich study - A prospective epidemiological study of depressive, neurotic and psychosomatic syndromes. I. Problem, methodology. Eur Arch Psychiat Neurol Sci 1984;234: 13-20.

44. Hoffmann N, Overall P. Factor structure of the SCL-90 in a psychiatric population. J Consult Clin Psychol 1978; 46:1187-1191.

45. Clark A, Friedman M. Factor structure and discriminant validity of the SCL-90 in a veteran psychiatric population. J Personality Assess 1983;47:396-404.

46. Holcomb W, Adams N, Ponder H. Factor structure of the symptom checklist-90 with acute psychiatric inpatients. J Consult Clin Psychol 1983;51:535-538.

47. Cyr J, McKenna-Foley J, Peacock E. Factor structure of the SCL-90-R: Is there one? J Personality Assess 1985; 49:571-578.

48. Alvir J, Schooler N, Borenstein M, Woerner M, Kane J. The reliability of a shortened version of the SCL-90-R. Psychopharmacol Bull 1988;24:242-246.

49. Kopman JA, Genco RJ, Grossi SG, Dunford RG, DeNardin E. Relationship of salivary cortisol to psychosocial risk indicators for periodontal disease. $J$ Dent Res 1996;75(Spec. Issue):101 (Abstr. 666).

50. Hynes GJ, Callan VJ, Terry DJ, Gallois C. The psychological well-being of infertile women after a failed IVF attempt: The effects of coping. $\mathrm{Br} J$ Med Psychol 1992;65:269-278.
51. McIntosh WA, Shifflett PA, Picou JS. Social support, stressful events, strain, dietary intake, and the elderly. Med Care 1989;27:140-153.

52. Stewart DE, Boydell K, Derzko C, Marshall V. Psychologic distress during the menopausal years in women attending a menopause clinic. Int J Psychiat Med 1992;22:213-220.

53. Kawachi I, Sparrow D, Vokonas PS, Weiss ST. Decreased heart rate variability in men with phobic anxiety (data from the Normative Aging Study). Am J Cardiol 1995; 75:882-885.

54. Hayward C. Psychiatric illness and cardiovascular disease risk. Epidemiol Rev 1995;17:129-138.

55. Scherwitz L, Perkins L, Chesney M, Hughes G, Sidney S, Manolio T. Hostility and health behaviors in young adults: The CARDIA Study. Coronary artery risk development in young adults study. Am J Epidemiol 1992;136:136-145.

56. Sherwin B. The impact of different doses of estrogen and progestin on mood and sexual behavior in postmenopausal women. J Clin Endo Metab 1991;72: 386-343.

57. Forsén A. Psychosocial stress as a risk for breast cancer. Psychother Psychosomatics 1991;55:176-185.

58. Schmader K, Studenski S, MacMillan J, Grufferman S, Cohen H. Are stressful life events risk factors for herpes zoster? J Am Geriatr Soc 1990;38:1188-1194.

59. Tennant CC, Langeluddecke PM, Fulcher G, Wilby J. Acute and chronic life event stress in coronary atherosclerosis. J Psychosom Res 1988;32:13-20.

60. Vandvik I, Hoyeraal H, Fagertun H. Chronic family difficulties and stressful life events in recent onset juvenile arthritis. J Rheumatol 1989;16:1088-1092.

61. Weinberger $M$, Hiner SL, Tierney WM. In support of hassles as a measure of stress in predicting health outcomes. J Behav Med 1987;10:19-31.

62. Sutton P. Acute dental caries, mental stress, immunity and the active passage of ions through the teeth. Med Hypotheses 1990;31(1):17.

63. Gardell B. Alienation and mental health in the modern industrial environment. In: Levi L, ed. Society Stress and Disease. London: Oxford University Press; 1971:148180.

Send reprint requests to: Dr. Robert J. Genco, State University of New York at Buffalo, School of Dental Medicine, Department of Oral Biology, Periodontal Disease Research Center, 115 Foster Hall, Buffalo, NY, 14214-3092. Fax: 716/829-2387; e-mail: rjgenco@acsu.buffalo.edu

Accepted for publication October 7, 1998. 